\title{
Thiamin, Selenium, and Copper Levels in Patients with Idiopathic Dilated Cardiomyopathy Taking Diuretics
}

\author{
Sérgio da Cunha, Francisco Manes Albanesi Filho, Vera Lúcia Freire da Cunha Bastos, \\ Domingos Senra Antelo, Mário Miranda de Souza
}

Rio de Janeiro, RJ - Brazil

\begin{abstract}
Objective - To analyze the association of thiamin, selenium, and copper serum levels with cardiac function in patients with idiopathic dilated cardiomyopathy using diuretics, and also to compare them with levels in control patients with no evidence of disease.
\end{abstract}

Methods - The study comprised 30 patients with heart disease and 30 healthy control individuals. Thiamin was analyzed by measuring the activity of erythrocytic transketolase and the effect of thiamin pyrophosphate. Selenium and copper serum levels were measured by hydride generation and flame atomic absorption spectrophotometry, respectively.

Results - Thiamin deficiency was observed in $10 \%$ of the control individuals and in $33 \%$ of the patients with heart disease $(p=0.02)$. The mean selenium and copper serum levels in control individuals and patients with heart disease were, respectively, $73.2 \pm 9.9 \mu \mathrm{g} / \mathrm{L}(56.5$ to $94.5 \mu \mathrm{g} / \mathrm{L})$ and $72.3 \pm 14.3 \mu \mathrm{g} / \mathrm{L}(35.5 \mathrm{to} 94 \mu \mathrm{g} / \mathrm{L})(p=0.77) ; 1.1 \pm 0.4 \mathrm{mg} / \mathrm{L}$ (0.6 to $1.8 \mathrm{mg} / \mathrm{L})$ and $1.2 \pm 0.4 \mathrm{mg} / \mathrm{L}(0.6$ to $2.2 \mathrm{mg} / \mathrm{L})(p=0.27)$. No association between the levels of these nutrients and cardiac function was observed.

Conclusion - Thiamin deficiency was significantly more frequent in patients with heart disease. No significant difference was observed between the mean selenium and copper serum levels in control individuals and in patients with heart disease. The results suggest possible benefits with thiamin replacement in patients taking diuretics.

Keywords: thiamin, selenium, copper, diuretics, cardiomyopathy

Hospital Universitário Pedro Ernesto, IBRAG e Geologia - UERJ Mailing address: Sérgio da Cunha - Rua Aquidaban, 184 - 20720-291 - Rio de Janeiro, RJ, Brazil - E-mail: sergio@netfly.cm.br

English version by Stela Maris C. e Gandour
In addition to the well-known adverse effects of the prolonged use of diuretics, thiamin deficiency induced by the use of diuretics has been reported since the late $1970 \mathrm{~s}^{1,2}$. An Israeli study ${ }^{3}$ assessed the hypothesis that prolonged treatment with furosemide in patients with heart failure was associated with a clinically significant deficiency of thiamin due to an increase in the urinary excretion of that nutrient. This deficiency was observed in 21 of the 23 patients with heart failure using furosemide and in only 2 of the 16 control individuals ( $\mathrm{p}<0.001)$. Thiamin replacement also caused a mean $13 \%$ increase in ejection fraction in 4 of the 5 patients who underwent echocardiography. This study used a technique reported by Brin ${ }^{4}$ to measure the effect of thiamin pyrophosphate on the erythrocytic transketolase activity. The mechanism by which diuretics increase the urinary excretion of thiamin is the increase in the urinary flow, common to all diuretics ${ }^{5,6}$. A randomized double-blind study ${ }^{7}$ assessed the effect of thiamin replacement on its organic level, on functional capacity, and on left ventricular ejection fraction in patients with heart failure using furosemide at the dosage $\geq 80 \mathrm{mg} /$ day. The effect of thiamin pyrophosphate was also assessed, and correction of the deficiency, increased diuresis, and an improvement in ejection fraction were observed. More recently, the thiamin status in rats receiving intraperitoneal doses of furosemide was assessed, and only the greater doses of furosemide induced thiamin deficiency, which could be reversed with replacement of that nutrient ${ }^{8}$.

The importance of selenium in human nutrition was emphasized in 1979, when Chinese scientists reported that its supplementation prevented the development of a cardiac disease known as Keshan disease in children living in areas with a selenium-poor soil ${ }^{9}$. The recommended selenium dietary allowances (RDA) in the United States of America are $55 \mu \mathrm{g} / \mathrm{day}$ for women and $70 \mu \mathrm{g} / \mathrm{day}$ for men. The selenium level in agricultural products is proportional to that nutrient's content in the soil where the agricultural products are cultivated. The geochemical composition of certain regions, such as Finland, New Zealand, the eastern coast of the USA, and China, reveals selenium deficiency in the soil ${ }^{10}$. This is the reason why studies carried out in a number of 
countries about the normal selenium serum level reported values ranging from $0.53 \mu \mathrm{mol} / \mathrm{L}$ in Finland to $2.01 \mu \mathrm{mol} / \mathrm{L}$ in Canada ${ }^{11}$ (tab. I). As far as we know, no similar study has been conducted in the Brazilian population, and, in our country, the geographical regions are as different as the composition of their soils.

The results of a number of studies about cardiac disease induced by selenium deficiency, such as Keshan disease that has been controlled with oral replacement of sodium selenite, have been published ${ }^{12-14}$. Most of the studies reported patients who had undergone long-term parenteral nutrition without selenium replacement, or patients with acquired immunodeficiency syndrome and severe undernourishment ${ }^{15-17}$. However, the association between low selenium levels and cardiovascular diseases remains controversial.

A low copper-content diet also results in cardiomyopathy in rats ${ }^{18}$. The National Research Council in the USA established the safe content of daily copper intake between 1.5 and $3.0 \mathrm{mg} /$ day. The exact mechanisms of cellular injury in copper deficiency have not yet been clarified. However, because the superoxide dismutase enzyme activity is reduced with copper deficiency, we can assume that the lesions found in the myocardial basement membrane result from the loss of protection against the free oxygen radicals produced ${ }^{18}$. The treatment with antioxidants of rats with cardiac disease induced by copper deficiency resulted in a reduction in cardiac hypertrophy and milder mitochondrial injury ${ }^{19}$. In 15-day-old pigs receiving a copper-deficient diet for 8 weeks, an increase in the heart weight/body weight ratio and electrocardiographic alterations were observed, confirming the findings in rats ${ }^{20}$. In patients undergoing myocardial revascularization, a lower concentration of microelements was observed, with the occurrence of heart failure in the early postoperative period, more frequent in patients with lower copper serum levels ${ }^{21}$.

The present study aimed at assessing thiamin, selenium, and copper serum levels in patients with idiopathic dilated cardiomyopathy using diuretics, and their comparison with those of an equal number of healthy individuals. The nutritional status of these patients with cardiac disease was assessed, as were the possible associations between undernourishment and the deficiency of the micronutrients

Table I - Mean selenium serum or plasma values in $\mu \mathrm{mol} / \mathrm{L}$ and $\mu \mathrm{g} / \mathrm{L}$ in adults of different countries ${ }^{6}$

\begin{tabular}{|lcr|}
\hline Region & $\mu \mathrm{mol} / \mathrm{L}$ & $\mu \mathrm{g} / \mathrm{L}$ \\
\hline Finland (Helsinki) & 0.53 & 41.73 \\
New Zealand (Dunedin) & 0.60 & 47.24 \\
Germany (Mainz) & 1.03 & 81.10 \\
Sweden (Lund) & 1.08 & 85.03 \\
Italy (Rome) & 1.14 & 89.76 \\
Japan (Hiroshima) & 1.24 & 97.63 \\
USA (Mort. Gr.) & 1.40 & 110.23 \\
England (Southampton) & 1.47 & 115.74 \\
Canada (Toronto) & 2.01 & 158.26 \\
\hline 1 $\mu \mathrm{g}=0.0127 \mu \mathrm{mol}$. & & \\
\hline
\end{tabular}

studied and between their serum levels and cardiac function, which was evaluated on echocardiography.

\section{Methods}

From 1999 to 2000, we carried out an observational study comprising 30 patients with idiopathic dilated cardiomyopathy and an equal number of healthy controls. All participants were informed about the nature of the study and its objectives and provided written informed consent. The research project was submitted to and approved by the committee on ethics and research at the Hospital Universitário Pedro Ernesto - UERJ. The groups were paired by age, sex, and skin color (white and nonwhite). The patients had been diagnosed with idiopathic dilated cardiomyopathy ${ }^{22}$ and were taking diuretics on a daily basis for a period $\geq 15$ days. Patients with renal and hepatic dysfunction and alcoholic individuals were excluded from the study ${ }^{23-25}$.

The patients underwent anamnesis, physical examination, laboratory tests, electrocardiography, single- and 2-dimensional echocardiography with Doppler, and nutritional assessment. The blood samples were withdrawn between 8 and 9 AM after a 12-hour fasting period. Routine biochemical measurements, including all electrolytes, hepatic function test, and lipid profile were performed.

Thiamin assessment was performed by measuring the erythrocytic transketolase activity and the effect of thiamin pyrophosphate, as reported by Myron Brin ${ }^{4}$. The following values were considered as normal limits: erythrocytic transketolase activity $\geq 800 \mu$ ghexose. $\mathrm{mL}^{-1} \cdot \mathrm{h}^{-1}$; effect of thiamin pyrophosphate $<16 \%$. Thiamin deficiency was defined as the simultaneous presence of low erythrocytic transketolase activity and the high effect of thiamin pyrophosphate ${ }^{26}$.

The sera in which selenium and copper were measured were stored in a refrigerator. The serum levels of the micronutrients were obtained by hydride generation and flame atomic absorption spectrophotometry, respectively according to the methodologies of Navarro et $\mathrm{al}^{27}$ and Terrés-Martos et al $^{28}$. The accuracy and precision of the method were tested with 2 sera with internationally recognized standardized selenium and copper concentrations as follows: 1) Contox trace metal serum control - Kaulson Laboratory, Inc., NJ, USA; 2) Seronorm trace elements serum, produced by SERO AS, Billingstad, Norway.

Nutritional evaluation was performed through nutritional history, anthropometric assessment, measurement of serum albumin, lymphocyte count, and global subjective assessment ${ }^{29,30}$.

The means were compared with the Student $t$ test for independent samples. We adopted $\mathrm{p} \leq 0.05$ as the significance level. The chi-square test was used to compare frequencies. To assess the association between numerical data, the correlation $(r)$ and determination $\left(r^{2}\right)$ coefficients were calculated.

\section{Results}

The composition of the groups studied is shown in table II. 


\begin{tabular}{|c|c|c|c|c|c|}
\hline \multicolumn{6}{|c|}{ Table II - Characteristics of the groups studied } \\
\hline \multirow[t]{2}{*}{ Group } & \multirow{2}{*}{$\begin{array}{c}\text { Mean age } \\
\text { (years) }\end{array}$} & \multicolumn{2}{|c|}{ Sex } & \multicolumn{2}{|c|}{ Color } \\
\hline & & & $\mathrm{F}$ & white & nonwhite \\
\hline Cardiac patients & $43.2 *$ & 23 & 7 & 22 & 8 \\
\hline Controls & $39.6 *$ & 23 & 7 & 22 & 8 \\
\hline
\end{tabular}

Furosemide dosages ranged from 20 to $160 \mathrm{mg}$ /day. Only 1 patient was not taking furosemide but was taking thiazide and spironolactone, and it appeared in the prescription of $10(33 \%)$ patients at the dosages of 25 ( 6 patients $-20 \%$ ) or $100 \mathrm{mg} /$ day (4 patients - 13\%). Six (20\%) patients took thiazides at the dosages of $12.5(3 \%), 25(7 \%)$, and $50 \mathrm{mg} /$ day (10\%). In 5(16\%) of these patients, furosemide was added, and, in $2(6 \%)$ of these patients, spironolactone was added. One (3\%) patient took a combination of the 3 diuretics. Forty-six percent of the patients with cardiac disease took furosemide doses $\geq 80 \mathrm{mg} /$ day.

The following medications were also used in the patients with cardiac disease: digoxin (97\%), angiotensin-converting enzyme inhibitors ( $86 \%$ ), amiodarone (13\%), coumarin anticoagulants (13\%), carvedilol (23\%), and acetylsalicylic acid (6\%). Eighty percent of the patients used the combination of digitalis, diuretics, and angiotensin-converting enzyme inhibitors.

The functional classes of the patients with cardiac disease (NYHA) were as follows: I, $17 \%$; II, $53 \%$; III, $23 \%$; and IV, $7 \%$ (tab. III).

\begin{tabular}{|c|c|c|c|}
\hline & Controls & Cardiac patients & $\mathrm{p}$ value \\
\hline \multicolumn{4}{|l|}{ Electrolytes: } \\
\hline Sodium $(\mathrm{mEq} / \mathrm{L})$ & 141 & 140 & NS \\
\hline Potassium $(\mathrm{mEq} / \mathrm{L})$ & 4.2 & 4.5 & NS \\
\hline Calcium (mg/dL) & 9.3 & 9.3 & NS \\
\hline Phosphorus (mg/dL) & 3 & 3.4 & NS \\
\hline Magnesium (mg/dL) & 2 & 1.9 & NS \\
\hline Chloride $(\mathrm{mEq} / \mathrm{L})$ & 102 & 99 & NS \\
\hline \multicolumn{4}{|l|}{ Hepatic tests: } \\
\hline AST (UI) & 21 & 36 & 0.001 \\
\hline ALT (UI) & 24 & 40 & 0.02 \\
\hline $\mathrm{TB}(\mathrm{mg} / \mathrm{dL})$ & 0.7 & 1.2 & 0.01 \\
\hline Glucose (mg/dL) & 93 & 98 & NS \\
\hline Creatinine $(\mathrm{mg} / \mathrm{dL})$ & 0.8 & 0.9 & NS \\
\hline $\mathrm{TC}(\mathrm{mg} / \mathrm{dL})$ & 210 & 213 & NS \\
\hline \multicolumn{4}{|l|}{ FC ( $\%$ of patients): } \\
\hline I & 100 & 17 & \\
\hline II & - & 53 & \\
\hline III & - & 23 & \\
\hline IV & - & 7 & \\
\hline $\mathrm{EF}(\%)$ & $\overline{65}$ & 31 & \\
\hline ETA $\left(\mu \mathrm{g}\right.$ hexose $\left.\cdot \mathrm{ml}^{-1} \cdot \mathrm{h}^{-1}\right)$ & $1002 \pm 155$ & $863 \pm 293$ & 0.02 \\
\hline ETP $(\%)$ & $13.8 \pm 7.2$ & $17.7 \pm 10.8$ & NS \\
\hline Thiamin deficiency $(\%)$ & 10 & 33.3 & 0.02 \\
\hline Selenium $(\mu \mathrm{g} / \mathrm{L})$ & $73.2 \pm 9.9$ & $72.3 \pm 14.3$ & NS \\
\hline Copper (mg/L) & $1.1 \pm 0.4$ & $1.2 \pm 0.4$ & NS \\
\hline \multicolumn{4}{|c|}{$\begin{array}{l}\text { ns- nonsignificant; AST- aspartate aminotransferase; ALT- alanine amino- } \\
\text { transferase; TB- total bilirubin; TC- total cholesterol; CF- functional class (New } \\
\text { York Heart Association); EF- ejection fraction; ETA- erythrocytic transketolase } \\
\text { activity; ETP- effect of thiamin pyrophosphate. }\end{array}$} \\
\hline
\end{tabular}

The groups had similar nutritional status according to both the objective and global subjective assessments, with cases of overweight and obesity.

No significant alterations were observed in the electrolytes or in the hepatic and renal functional tests in either group. Dyslipidemia was highly prevalent both in patients with cardiac disease and in the controls $(83.3 \%$ and $76.6 \%$, respectively), table III.

Left ventricular ejection fraction (LVEF) in patients with cardiac disease ranged from 12 to $57 \%$ (mean $=31 \%$ ). The subjective assessment of left ventricular function showed severe systolic dysfunction in $83.3 \%$ of the patients, moderate systolic dysfunction in $10 \%$, and mild systolic dysfunction in $6.7 \%$ of the patients. Left bundle-branch block was observed in $60 \%$ of the patients with cardiac disease. Coronary angiography was performed in $50 \%$ of the patients with cardiac disease and was normal in all of them.

The means of the erythrocytic transketolase activity in the controls and in patients with cardiac disease were $1002 \pm 155$ and $863 \pm 293 \mu$ g glucose. $\mathrm{mL}^{-1} \cdot \mathrm{h}^{-1}$ (ranges: 706 to 1347 and 145 to $1344 \mu \mathrm{g}$ glucose. $\mathrm{mL}^{-1} \cdot \mathrm{h}^{-1}$ ), respectively $(\mathrm{p}=0.02)$. The mean effect of thiamin pyrophosphate was $13.8 \pm 7.2 \%$ (1.4 to $31.5 \%$ ) in the controls, and $17.7 \pm 10.8 \%$ (1.3 to $46.2 \%)$ in the patients with cardiac disease $(p=0.12)$. Thiamin deficiency was observed in 3 controls and in 10 patients with cardiac disease $(\mathrm{p}=0.02)$, table III. No significant difference in the frequency of thiamin deficiency was observed between patients with cardiac disease taking furosemide doses $<80 \mathrm{mg} /$ day and those taking furosemide doses greater than that value $(p=0.07)$. The use of spironolactone did not decrease thiamin deficiency frequency in the patients studied with cardiac disease $(p=0.28)$. Thiamin deficiency was not more frequent in the patients taking the furosemide/thiazide combination $(\mathrm{p}=0.17)$. No association was observed between thiamin serum level and left ventricular ejection fraction in patients with cardiac disease in the assessment performed either through erythrocytic transketolase activity $(r=-0.05)$ or through the effect of thiamin pyrophosphate $(\mathrm{r}=0.07)$. No significant difference was observed in the mean left ventricular ejection fraction of patients with cardiac disease who had thiamin deficiency $(\mathrm{LVEF}=32.6 \%)$ and those who did not have thiamin deficiency $(\mathrm{LVEF}=30.7 \%), \mathrm{p}=0.68$. None of the 10 patients with thiamin deficiency was undernourished.

In regard to selenium serum level, the accuracy (exactness) and precision (reproducibility) of the method are shown in table IV. With the reference material of Seronorm, $102.4 \%$ accuracy and $5.3 \%$ precision were obtained.

The mean selenium serum levels in controls and patients with cardiac disease were, respectively, $73.2 \pm 9.9 \mu \mathrm{g} /$ $\mathrm{L}(56.5$ to $94.5 \mu \mathrm{g} / \mathrm{L})$ and $72.3 \pm 14.3 \mu \mathrm{g} / \mathrm{L}(35.5$ to $94 \mu \mathrm{g} / \mathrm{L})$ with $\mathrm{p}=0.77$. The results are visually compared in figure 1 . No association was observed between selenium serum levels and left ventricular ejection fraction $\left(\mathrm{r}=-0.10 ; \mathrm{r}^{2}=0.01\right)$.

In regard to copper serum level, the method's accuracy and precision observed with the use of the reference mate- 


\begin{tabular}{|c|c|c|c|c|c|}
\hline & \multirow[t]{2}{*}{ Material } & \multicolumn{2}{|c|}{ Concentration } & \multirow{2}{*}{$\begin{array}{c}\text { Accuracy } \\
(\%)\end{array}$} & \multirow{2}{*}{$\begin{array}{l}\text { Precision } \\
\text { RSD (\%) }\end{array}$} \\
\hline & & Certified & $\overline{\text { Measure }}$ & & \\
\hline & \multicolumn{4}{|c|}{ NIST-RM 3149} & 5.3 \\
\hline Copper (mg/L) & $\begin{array}{c}\text { Contox } \\
\text { RM- } 0148\end{array}$ & $0.8 \pm 12$ & $0.8 \pm 0.03$ & 98.7 & 3.8 \\
\hline $\begin{array}{l}\text { RSD- relative st } \\
\text { RM-reference m }\end{array}$ & $\begin{array}{l}\text { andard devia } \\
\text { terial. }\end{array}$ & ion; NIST- & National Inst & titute of $\mathrm{S}$ & Standards; \\
\hline
\end{tabular}

rial Contox are shown in table IV. Accuracy of $98.7 \%$ and precision of $3.8 \%$ were obtained.

The mean copper serum levels in controls and patients with cardiac disease were, respectively, $1.1 \pm 0.4 \mathrm{mg} / \mathrm{L}$ ( 0.6 to $1.8 \mathrm{mg} / \mathrm{L})$ and $1.2 \pm 0.4 \mathrm{mg} / \mathrm{L}(0.6$ to $2.2 \mathrm{mg} / \mathrm{L}), \mathrm{p}=0.27$. Visual comparison of the data is shown in figure 2 . No association was observed between copper serum levels and left ventricular ejection fraction in patients with cardiac disease $(r=-$ $0.25 ; \mathrm{r}^{2}=0.06$ ).

\section{Discussion}

Due to the lack of Brazilian studies reporting the normal range in our population for erythrocytic transketolase activity, for the effect of thiamin pyrophosphate, and for selenium and copper serum levels, the formation of a control group with individuals with no evidence of disease or use of any medication paired by age, sex, skin color, and nutritional status was required.

From the clinical point of view, most patients with cardiac disease were compensated in NYHA functional classes I or II, even though they had severe myocardial disease according to echocardiographic data $(83.3 \%$ had severe systolic dysfunction).

Both groups had similar nutritional profiles as follows: mean BMI of controls and patients with cardiac disease, respectively, 26.2 and $26 \mathrm{~kg} / \mathrm{m}^{2}$; mean body fat percentage, respectively, 24.3 and $25 \%$; mean CMB, respectively, 26 and $24.4 \mathrm{~cm}$; and no significant alteration in serum albumin. Overweight and obesity were present in both groups.

Three patients with cardiac disease had an increase in hepatic aminotransferases (AST and ALT) and total bilirubin greater than twice the normal limit. On echocardiography, these three patients had severe systolic dysfunction, 2 of whom had left ventricular ejection fraction $<20 \%$. On physical examination, they had tender hepatomegaly and jugular venous distension, suggesting hepatic congestion as the cause of the enzymatic alteration, which is the reason why we did not find it necessary to measure hepatitis viral markers.

Assessment of thiamin levels should include erythrocytic transketolase activity and the effect of thiamin pyrophosphate on erythrocytic transketolase activity, which reflects the percentage of increase in this activity after the

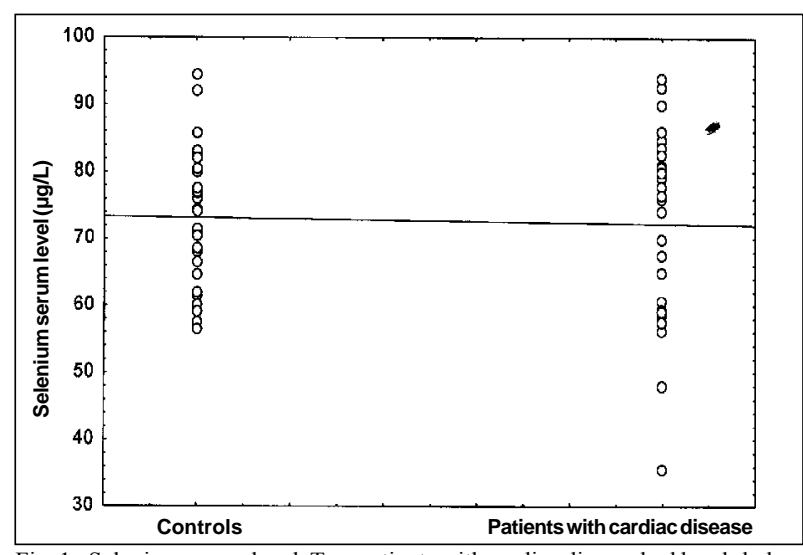

Fig. 1 - Selenium serum level. Two patients with cardiac disease had levels below $50 \mathrm{mg} / \mathrm{L}$.

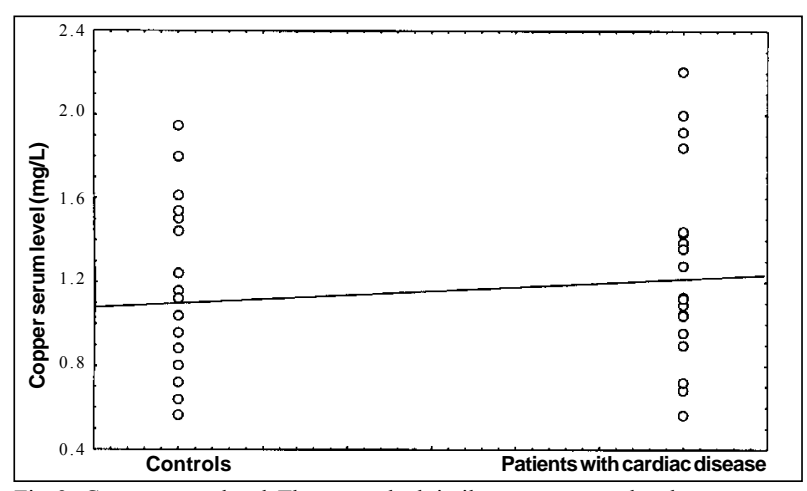

Fig. 2 - Copper serum level. The groups had similar copper serum levels.

addition of thiamin pyrophosphate to the hemolysate. However, until the present time, no consensus exists in regard to the normal levels of erythrocytic transketolase activity due to the use of different methods of measurement by several laboratories ${ }^{30}$. Two aspects should be considered in the analysis of the erythrocytic transketolase activity ${ }^{31}:$ a) the method involves the activity of other erythrocytic enzymes, such as ribose isomerase and xylulose epimerase, which do not depend on thiamin, and, in case of their deficiency, this may influence the result of the test, because no increase in erythrocytic transketolase activity will be detected (assessed by the formation of hexoses in the hemolysate), and occasional cases of thiamin deficiency will not be identified; $b$ ) thiamin deficiency may also cause a reduction in apotransketolase and a weak response of that to thiamin pyrophosphate, with the same consequence. These aspects show the importance of considering the simultaneous existence of low erythrocytic transketolase activity and the high effect of thiamin pyrophosphate as a criterion for the diagnosis of thiamin deficiency.

Dietary standardization was not adopted in this study because the objective of the study was to assess the status of the micronutrients in the nutritional reality of its participants. By limiting thiamin intake to $1.5 \mathrm{mg} /$ day, Seligmann et $\mathrm{al}^{3}$ assessed the role played by diuretics in thiamin depletion, but they imposed a regimen of that micronutrient ingestion 
on study participants, which may not have matched the dietary reality of the patients. The usual ingestion of a higher thiamin content, both due to the presence of food richer in that nutrient or due to its conservation and preparation avoiding the action of thiaminases, could overcome the losses imposed by the diuretics, reducing the clinical importance of the increased urinary excretion of thiamin in that population.

Daily ingestion of the nutrients was not estimated in the study because of the difficulty in precisely establishing the nutrient's content in the food ingested, as well as their amount, in the absence of a standardized diet. The influences of the processes of food conservation and preparation in the bioavailability of thiamin also contributed making this assessment difficult ${ }^{30}$, as did ignorance about the selenium and copper contents in food cultivated in Brazil.

In a previous study ${ }^{32}$, considering only the elevated effect of thiamin pyrophosphate as a criterion for thiamin deficiency, a possible effect of spironolactone as a saver of thiamin spoliation induced by furosemide was observed. In the present study, a significant difference between the means of the effect of thiamin pyrophosphate in takers and nontakers of spironolactone was observed; however, adopting the new criterion here presented (low erythrocytic transketolase activity and elevated effect of thiamin pyrophosphate), no significant difference in the prevalence of thiamin deficiency between the groups was observed $(p=0.28)$. Even though greater thiamin spoliation should be expected in patients taking the combination furosemide/ thiazide due to the increased urinary flow, it was not observed in the present study, maybe because of the small number (5) of patients taking that combination.

The mean selenium serum level in controls $(73.2 \pm$ $9.9 \mu \mathrm{g} / \mathrm{L}$ ) was similar to that reported by Navarro et a ${ }^{27}$ in Spain $(74.90 \mu \mathrm{g} / \mathrm{L})$; when compared with those shown in table I, it is among the lowest levels, above only those reported in Finland and New Zealand, regions with seleniumpoor soils. Despite the report by Inoko et al ${ }^{33}$ of a case of cardiomyopathy related to the selenium serum level of $62 \mu \mathrm{g} / \mathrm{L}$, the most frequently reported levels in the literature are below $50 \mu \mathrm{g} / \mathrm{L}^{11,13,15}$. In the Chinese cardiomyopathy cases, the selenium serum levels reported were below $30 \mu \mathrm{g} / \mathrm{L}^{11}$. However, we do not know the role played by intermediate serum levels in worsening the already present cardiomyopathy or cardiomyopathy with other etiologies. No association was observed between the selenium and copper levels in patients with cardiac disease and their cardiac function assessed by left ventricular ejection fraction. We believe that this was due to the existence of another etiological mechanism for the myocardial disease of the patients studied, in addition to the record of only 2 cases with low selenium serum levels, which did not allow a better evaluation of the possible influence of this deficiency in worsening the underlying disease.

The mean copper serum level in the control group $(1.09 \pm 0.39 \mathrm{mg} / \mathrm{L})$ is similar to that reported by Terrés-Martos et $\mathrm{al}^{28}(1.10 \mathrm{mg} / \mathrm{L})$, and to others observed in other countries, such as the USA $(0.9 \pm 0.03 \mathrm{mg} / \mathrm{L})^{34}$ and Japan $(0.98 \pm$ $0.11 \mathrm{mg} / \mathrm{L})^{35}$. No significant difference was observed between the mean copper serum level in controls and that in patients with cardiac disease $(p=0.27)$, suggesting a good content of that element in the food ingested by the patients studied. The preferentially hepatic excretion of copper minimizes the influence of the diuretics in copper spoliation.

In this study, thiamin deficiency was significantly more frequent in patients with cardiac disease, occurring in $1 / 3$ of the patients, raising the possibility that the systematic replacement of that micronutrient might contribute to better myocardial performance in patients taking diuretics for prolonged periods. However, it is worth emphasizing the nonexistence in the Brazilian market of a commercial product with a thiamin unit dose adequate for that purpose. The only product available for oral administration has $300 \mathrm{mg} /$ tablet, which seems excessive, even though the minimum dose necessary to compensate for the losses induced by diuretics is yet to be defined. As thiamin deficiency has not been associated with protein-caloric undernourishment, we should consider the possibility of that vitamin deficiency even in the absence of the classical signs of undernourishment.

No significant difference in the mean selenium and copper serum levels was observed between controls and patients with cardiac disease. However, 2 patients with cardiac disease $(6.6 \%)$ had selenium $<50 \mu \mathrm{g} / \mathrm{L}$, which we consider significant, because such levels have already been reported as sufficient to induce myocardial dysfunction ${ }^{6,8,10}$. This finding raises the question of the possible benefit of selenium replacement in patients with idiopathic dilated cardiomyopathy refractory to the conventional therapeutic schemes. Even though serum measurement should precede replacement of the microelement, we should consider the difficulty of this procedure in Brazil, especially in public health units. However, the results here presented seem not to justify the systematic replacement of selenium and copper in idiopathic dilated cardiomyopathy.

\section{References}

1. Yui Y, Fujiwara H, Mitsui H. Furosemide-induced thiamine deficiency. Jpn Circ J 1978; 4: 744.

2. Yui Y, Itokaua Y, Kawai C. Furosemide-induced thiamine deficiency. Cardiovasc Res 1980; 14: 537-40.

3. Seligmann $H$, Halkin $H$, Rauchfleisch S, et al. Thiamine deficiency in patients with congestive heart failure receiving long-term furosemide therapy: a pilot study. Am J Med 1991; 91: 151-5.

4. Brin M. Transketolase and the TPP effect in assessing thiamine adequacy. In: MCcormic DB, Wright LD. Methods in Enzymology, Vitamins and Coenzymes. New York: Academic Press, 1970; vol. 18: 125-33. 
5. Department of Medicine, Sheba Medical Center. Urinary thiamine excretion in the rat: effects of furosemide, other diuretics, and volume load. J Lab Clin Med 1999; 134: 232-7.

6. Rieck J, Halkin H, Almog S, et al. Urinary loss of thiamine is increased by low doses of furosemide in healthy volunteers. J Lab Clin Med 1999; 134: 238-43.

7. Shimon I, Shlomo A, Vered Z, et al. Improved left ventricular function after thiamine supplementation in patients with congestive heart failure receiving long-term furosemide therapy. Am J Med 1995; 98:485-90.

8. Dmerc, United Arab Emirates University, Al-Ain. Thiamin status in furosemidetreated rats. Pharmacol Res 2000; 42: 21-4.

9. Keshan Disease Research Group. Observations on effect of sodium selenite in prevention of Keshan disease. Chin Med J Engl 1979; 92: 471-6.

10. Burk RF, Levander OA. Selenium. In: Shils ME, Olson JA, Shike M, Ross AC Modern Nutrition in Health and Disease, $9^{\text {th }}$ ed.. Baltimore: Willians \& Willians, 1999: 265-76

11. Lockitch G. Selenium: clinical significance and analytical concepts. Crit Rev Clin Lab Sci 1989; 27: 483-541.

12. Reeves WC, Marcuard SP, Willis SE, Movahed A. Reversible cardiomyopathy due to selenium deficiency. J Parent Ent Nut 1989; 13: 663-5.

13. Oster O, Prellwitz W, Kasper W, Meinertz T. Congestive cardiomyopathy and selenium content of serum. Clin Chim Acta 1983; 128: 125-32.

14. Collipp PJ, Chen SY. Cardiomyopathy and selenium deficiency in a two-yearold girl. N Engl J Med 1981; 304: 1304-5.

15. Fleming CR, LieJT, MaccallJT, etal. Selenium deficiency and fatal cardiomyopathy in a patient on home parenteral nutrition. Gastroenterology 1982; 83: 689-93.

16. Quercia RA, Korn S, O'neillD, etal. Selenium deficiency and fatal cardiomyopathy in a patient receiving long-term home parenteral nutrition. Clin Pharm 1984; 3: 531-5

17. Duorkin BM, Antonecchia PP, Smith F, et al. Reduced cardiac selenium content in the acquired imunodeficiency syndrome. J Parent Ent Nut 1989; 13: 644-7.

18. Medeiros DM, Davidson J, Jenkins JE. A unified perspective on copper deficiency and cardiomyopathy. Proc Soc Exp Biol Med 1993; 203: 262-73.

19. ViestenzKE, Klevay LM.A randomized trial of copper therapy in rats with eletrocardiographic abnormalities due to copper deficiency. Am JClin Nutr 1982;35:258-66.

20. Wildman RLH, Medeiros DM, Hamlin R, et al. Aspects of cardiomyopathy in copper-deficient pigs - electrocardiography, echocardiography, and ultrastructural findings. Biol Trace Elem Res 1996; 55: 55-70.

21. Dementéva II, Adrianova MIL, Dzemeshkevich SL, Iavorovskii AG, Lokshin LS Changes in the content of microelements - copper, zinc, iron-in the blood of patients following cardiopulmonary bypass. Anesteziol Reanimatol 1993; 4: 50-3.
22. Report of 1995 World Health Organization/International Society and Federation of Cardiology Task Force on the definition and classification of cardiomyopathies. Circulation 1996; 93: 841-3.

23. Burch GE, Gilles TD. Alcoholic cardiomyopathy: concept of disease and its treatment. Am J Med 1971; 50: 141-5.

24. Richardson PJ, Wodak AA. Alcohol-induced heart muscle disease. In: Symons C, Evans T, Mitchell AG. Specific Heart Muscle Disease. Bristol: Wright P.S.G., 1983: 99-122.

25. Gillet $\mathrm{C}$, Julliere $\mathrm{Y}$, Pirollet $\mathrm{P}$, et al. Alcohol consumption and biological markers for alcoholism in idiopathic dilated cardiomyopathy:case-controlled study. Alcohol Alcoholism 1992; 27: 353-8.

26. Tanphaichitr V, Wood B. Thiamin. In: Shils ME, Olson JA, Sihe M, Ross AC Modern Nutrition in Health and Disease. $8^{\text {th }}$ ed. Philadelphia: Lea \& Febiger, 1994: 359-65.

27. Navarro M, Lopez H, Ruiz ML, et al. Determination of selenium in serum by hydride generation atomic absortion spectrometry for calculation of daily dietary intake. Sci Total Environ 1995; 175: 245-52.

28. Terrés-Martos C, Navarro-Alarcón M, Martín-Lagos F, López-GA H, LópezMartinez MC. Determination of copper levels in serum of helthy subjects by atomic absorption spectrometry. Sci Total Environ 1997; 198: 97-103.

29. Baxter YC. Avaliação nutricional do cardiopata. Rev Soc Cardiol Est São Paulo 1997; 7: 445-57.

30. Dehoog S. The assessment of nutritional status. In: Mahan LK, Escott-Stump S Food, Nutrition and Diet Therapy. $9^{\text {th }}$ ed. Philadelphia: WB Saunders Co., 1996 361-78.

31. Sauberlich HE. Biochimical alterations in thiamine deficiency - Their interpretation. Am J Clin Nutr 1967; 20: 528-42.

32. Cunha S, Albanesi $\mathrm{F}^{\circ} \mathrm{FM}$. Espoliação por tiamina com o uso de diuréticos na cardiomiopatia dilatada. Arq Bras Cardiol 2000; 74(supl. 1): 80.

33. Inoko M, Konishi T, Matsusue S, Kobashi Y. Midmural fibrosis of left ventricle due to selenium deficiency. Circulation 1998; 98: 2638-9.

34. Lukaski HC, Hoverson BS, Gallagher SK, Bolouchuk WW. Physical training and copper, iron and zinc status of swimmers. Am J Clin Nutr 1990; 51: 1093-9.

35. Yoshida D, Ykeda Y, Nakazawa S. Quantitative analysis of copper, zinc and copper/zinc ratio in selected human brain tumors. J Neurooncol 1993; 16 : 109-15. 